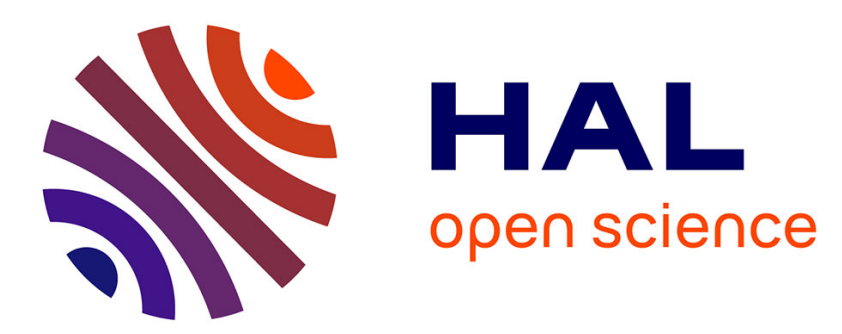

\title{
EMITTING OF PHASE CONJUGATE ULTRASOUND WAVE INTO LIQUID BY PARAMETRICALLY EXCITED FERRITE
}

\author{
A. Brysev, F. Bunkin, L. Krutiansky, V. Preobrazhenskii, Yu. Pyl’Nov, A. \\ Stachovsky
}

\section{To cite this version:}

A. Brysev, F. Bunkin, L. Krutiansky, V. Preobrazhenskii, Yu. Pyl'Nov, et al.. EMITTING OF PHASE CONJUGATE ULTRASOUND WAVE INTO LIQUID BY PARAMETRICALLY EXCITED FERRITE. Journal de Physique IV Proceedings, 1992, 02 (C1), pp.C1-895-C1-898. 10.1051/jp4:19921195 . jpa-00251160

HAL Id: jpa-00251160 https://hal.science/jpa-00251160

Submitted on 1 Jan 1992

HAL is a multi-disciplinary open access archive for the deposit and dissemination of scientific research documents, whether they are published or not. The documents may come from teaching and research institutions in France or abroad, or from public or private research centers.
L'archive ouverte pluridisciplinaire HAL, est destinée au dépôt et à la diffusion de documents scientifiques de niveau recherche, publiés ou non, émanant des établissements d'enseignement et de recherche français ou étrangers, des laboratoires publics ou privés. 


\title{
EMITTING OF PHASE CONJUGATE ULTRASOUND WAVE INTO LIQUID BY PARAMETRICALLY EXCITED FERRITE
}

\author{
A.P. BRYSEV, F.V. BUNKIN, L.M. KRUTIANSKY*, V.L. PREOBRAZHENSKII*, \\ Yu.V. PYL'NOV* and A.D. STACHOVSKY \\ General Physics Institute, Russian Academy of Sciences, 38 Vavilov st., Moscow 117942, USSR \\ ${ }^{*}$ MoscowInstitute of Radio Engineering, Electronics and Automation, 78 Vernadskogo pr., Moscow \\ 117454, USSR
}

\begin{abstract}
Phase conjugate sound waves at $6 \mathrm{MHz}$ generated by polycrystaline ferrite sample at conditions of parametric magnetic field pumping over the threshold of absolute instability were studied in liquid. Conforming images of phase fronts for incident and conjugate waves were obtained. An angular anisotropy of effectivity connected with sample geonetry was discovered and a method for it smoothing out is proposed. Maximum gain of acoustic
\end{abstract} wave in water was $43 \mathrm{~dB}$ ( $60 \mathrm{~dB}$ in ferrite).

Methods of ultrasonic wave phase conjugation ( WPC) with amplification by using parametric echo in piezoelectrics /1/ have been proposed by several authors $/ 2,3 /$. A practical application of WPC effect in acoustic inaging system was recently reported /4/. A parametric echo in magnets $/ 5 /$ and perspectivity of magnetic dielectrics with strong manetoelastic interaction as active media for WPC has also been described $16,7 /$. A glant amplification of conjugate wave at $30 \mathrm{MHz}$ in regenerative regime has been discovered in ferrite /7/. In order to verify conjugate wave properties, experiments on stroboscopio visualization of acoustic fields in solid were carried out for woves with wide spatial spectra $/ 8 /$. The impulse WPC process in magnets with pumping field amplitude over a threshold of absolute parametric instability has been studied by authors $/ 8,3 /$.

In this paper experimental observation results of phase conjugate ultrasonic waves, emitted by ferrite sample in water in the regime of overthreshold parametric pump by magnetic field are reported.

The experimental setup is shown in Fig. 1(a). A polycrystalline $\mathrm{Ni}$ - ferrite sample $28 \mathrm{~mm}$ in diameter with pump coil on it was slightly immersed in a water which has been poured in a transparent basin. A direct magnetic field $(\boldsymbol{H}=400 \mathrm{Oe}$ ) was applied along the sample axis. A plane ultrasonic transducer $18 \mathrm{~mm}$ in diameter was placed at the underwater end of an angle meter lever which axis 0 lied in the plane of the sample surface. This arrangement permitted irradiation of the sample surface with plane ultrasonic waveg from various directions. The accuracy of angular measuring was $15^{\circ}$.

At the instant when incident ultrasonic pulse ( $6 \mathrm{MHz}, 30 \mathrm{\mu s}$ duration, from the transducer reached the active zone with coil the pumping rf pulse ( $12 \mathrm{MHz}, 40 \div 100 \mu$ s duration) was switched on. A pumping field strength amplitude $h=60$ oe was approximately twice as large as absolute instability threshold value. A generated pulse of conjugate wave was recelved by the same transducer. Pump 
souroe powen in experinents was doont 1.2 kw. Maximar intensity and goin of conjuede wave in water was 4 Wich and 43 de 60 ab in fexrle , respestively

The aneviat depondence of a normaliaed output sisnel amplitude for a $150 \mathrm{~mm}$ length sample is shown in Fig. 1 (b) by curve 1 . Curve 2 show the amplitude of signal, fefleoted from the sample surace and it was used to indicate the normel direotion, velocities of longitudinal and transverse waves in the sample were $V_{e}=7.13 \mathrm{~km} / \mathrm{s}$, $V_{t}=3.34 \mathrm{~km} / \mathrm{s}$ and critio angles for water-ferrite interface $\varphi_{e}=$ $12^{\circ} 6^{\circ}, \varphi_{t}^{c}=26^{\circ} 42^{\circ}$. Angular positions of maxima in experiments

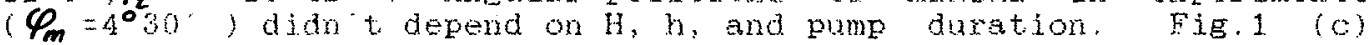
shows the same experiment but with a sample of $100 \mathrm{~mm}$ length. In that case maxime were observed at ang]eg $\varphi_{m}=14^{\circ}$ which exceeded $\mathscr{C}^{c}$. The mentioned anisotropy is likely due to the sample geometry in conditions of a complicated parametrical interaction in a multi-mode wavepuide structure.

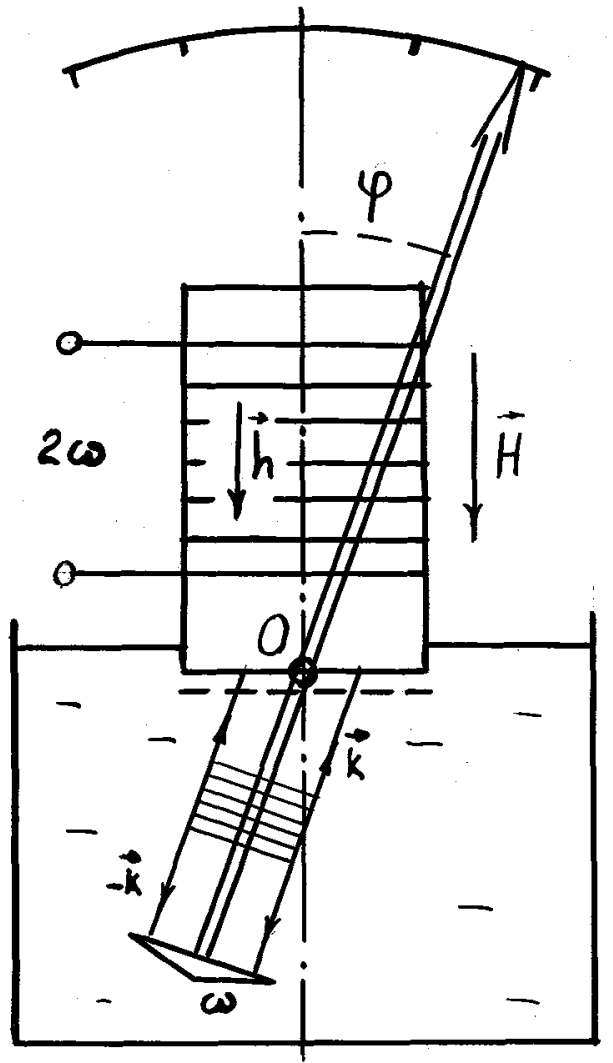

(a)

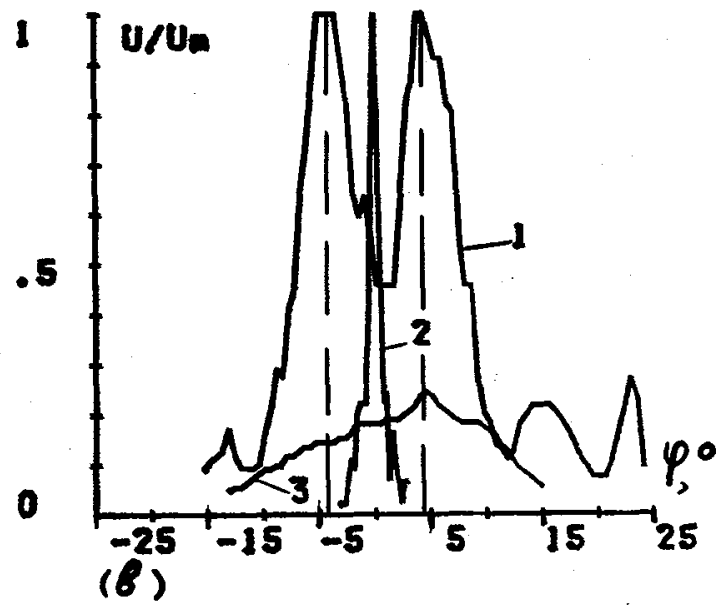

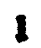

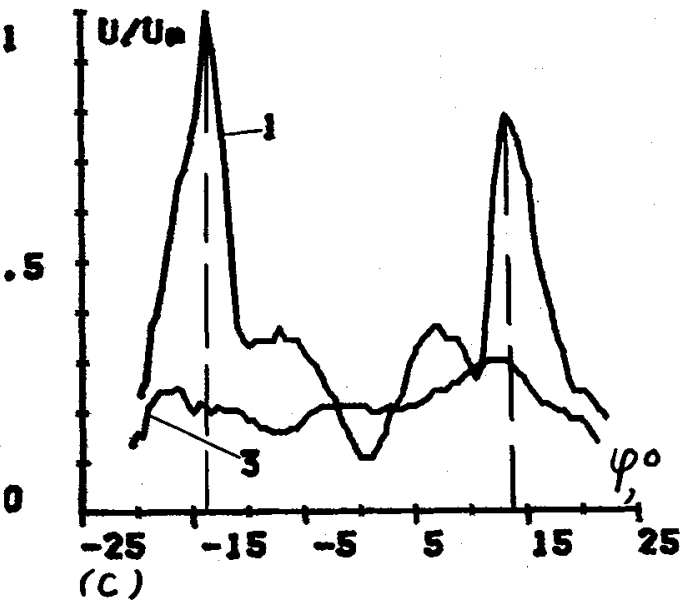

Fig. 1. - Experimental setup (a) and normalised output voltages (b), (c) in angular effectivity measuring. (b) - $150 \mathrm{~mm}$ sample, (c) - $100 \mathrm{~mm}$ sample. 1 - conjugate wave, 2 - refleotion from the sample front surface, 3 - conjugate wave in the presence of random plate. 
In order to smooth out the angular dependencies a special plate which caused random-like phase distortions in wave fronte was placed close to the sample surface. Curve 3 in Fig. 1 (b), (c) indicates that with this phase plate the angular dependencies became more smooth.

To be sure that wave pheses are really conjugate one should compare images of radiated and received wave fronts. This experiment was carried out using shileren method. A laser light. beam propagated parallel to axis 0 . Stroboscopic regime pernjtted time separation of incident and conjugate waves. Images of wave fronts for two angular positions of the transducer are presented in Flg. 2 and look like straight black and white gtrips, A good mutual

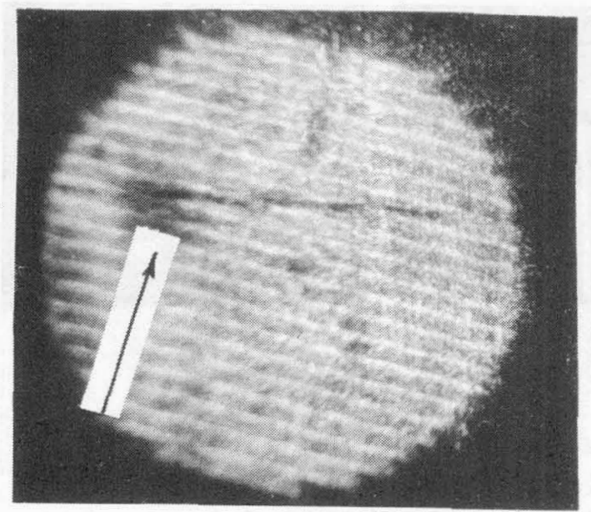

(a)

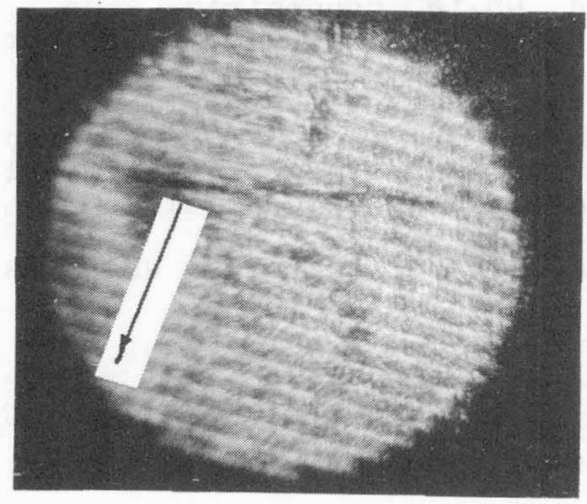

(C)

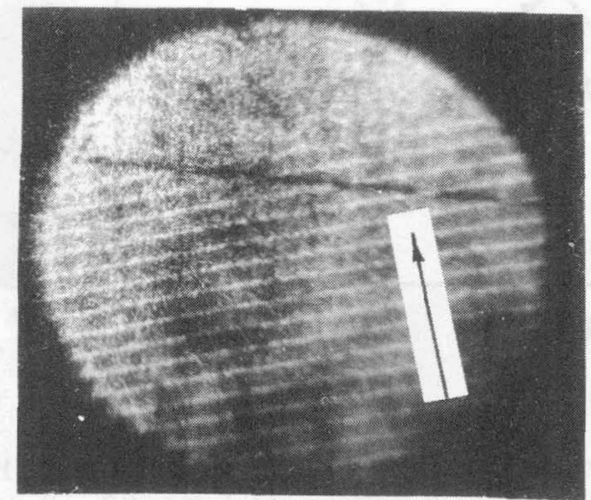

(b)

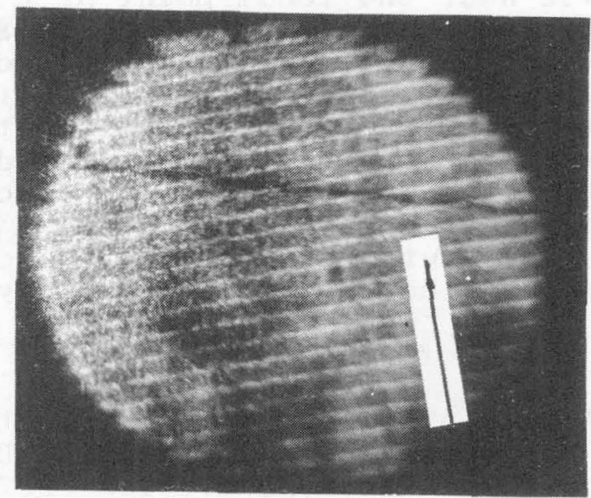

(d)

Fig 2. - Inages of wave fronts. (a), (b) - incident waves at $\varphi=-15^{\circ}$ and $+15^{\circ}$ respectively; $(\mathrm{c})$, (d) - conjugate waves. A black horizontel Iine is an angular position basis. Arrows show waves directions.

correspondence can be noticed. The angular difference of incident and reradiated wave fronts was less than $1^{\circ}$.

In experiment which setup is shown in Fig. 3 (a) an inoident wave from transducer has been focused in a point $F$ by oylindric reflector and then it carne to the sample. Conjugate wave propagated. from the sample back to the focus. 


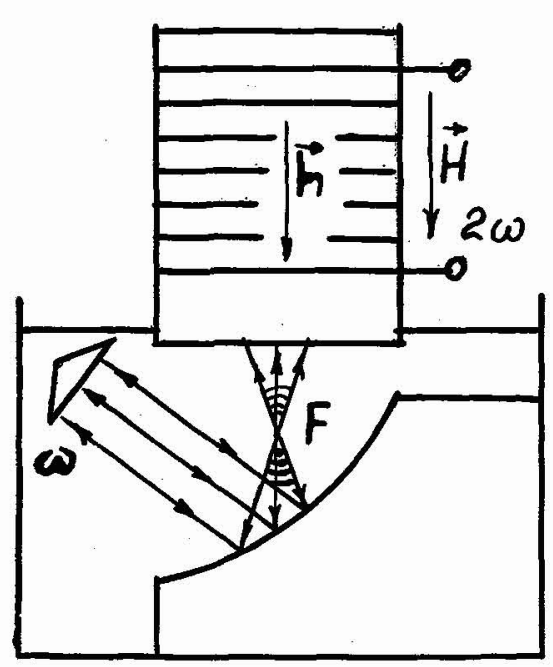

(a)

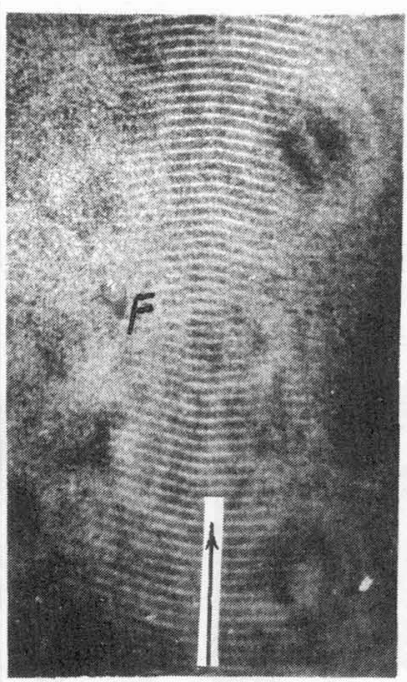

(b)

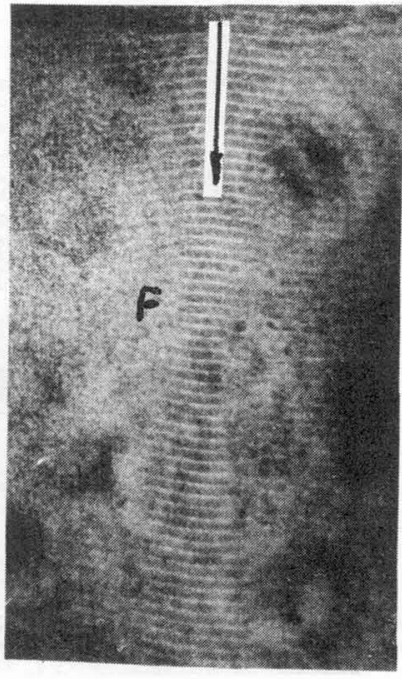

(c)

Figure 3. Experimental setup (a) and images of fronts of incident (b) and confugate $(c)$ waves in experiments with focused wave. Arrows show a direction of wave propagation. F - focal area.

Fig. 3 (b), (c) shows wave front images of incident and conjugate waves near the focal point as black and white concentric arcs. A satisfactory conformity can be seen in that case also. In both optical experiments the sample of $100 \mathrm{~mm}$ length was used.

In conclusion we wish to note that the above experiments on direct observation of wave fronts in liquid as well as anisotropy investigations have demonstrated the applicability of parametric interaction in ferrite to sound wave phase conjugation with amplification.

The authors gratefully acknowledge I.N. Andreeva who has supplied the samples and N.N. Ryshov for developing them.

\section{References}

/1/ R.B. Thompson and C.F. Quate, J.Appl.Phys.42,(1971). 907

$/ 2 /$ A.P. Brysev, F.V. Bunkin, D.V. Vlasov, and Yu.E. Kazarov, Sov. Tech. Phys. Lett. 8 , no. $5,(1982) .237$

/3/ M.Ohno, App L. Phys. Lett.54, (1989). 1979

/4/ M.Ohno, Jap.J.Appl. Phys. 29, sup1.29-1, (1989). 299

$15 /$ H. van de Vaart, D.H.Lyons, and R.W.Damon, J.App1. Phys. 38, (1967) 360

/6/ V.A. Krasiintkov, T.A. Mamatava, and V.G. Prokoshev, Sov.Fiz. Tv. Tela, 28, (1988) (Russian).615

/7/ A.P.Brysev, F.V.Bunkin, D.V. Vlasov, L.M. Krutiansky, V.L. Preobrazhensky, A.D. Stachovsky, Sov. Phys.Acoustics.34, (1988).567 /8/ A.P.Brysev, F.V.Bunkin, N.A. Ekonomov, L.M. Krutiansky, V.L. Preobrazhensky, Yu.V. Pyl nov, A.D. Stachovsky, and D.V.Vlasov, Col. de Phys. 51 (1990), C2-73.

19/ A.P.Brysev, F.V.Bunkin, N.A. Ekonomov, L.M. Krutiansky, V.L. Preobrazhensky, V.N.Streltsov, Yu.V. Pyl'nov, A.D. Stachovsky, and D.V.Vlasov, Optic.\& Acous.Rev.1, (1990)107 